\title{
Microcondylaea bonellii as a new host for the European bitterling Rhodeus amarus
}

\author{
Ronaldo Sousa ${ }^{1, *}$, Arthur E. Bogan ${ }^{2}$, Duarte V. Gonçalves ${ }^{3}$, Jasna Lajtner ${ }^{4}$, Vincent Prié ${ }^{5}$, \\ Nicoletta Riccardi ${ }^{6}$, Spase Shumka ${ }^{7}$, Amílcar Teixeira ${ }^{8}$, Maria Urbańska ${ }^{9}$, Simone Varandas ${ }^{10}$ \\ and Manuel Lopes-Lima ${ }^{3,11}$ \\ ${ }^{1}$ CBMA - Centre of Molecular and Environmental Biology, Department of Biology, University of Minho, Campus Gualtar, \\ Braga, Portugal \\ ${ }^{2}$ North Carolina State Museum of Natural Sciences, 11 West Jones Street, Raleigh, USA \\ ${ }^{3}$ CIIMAR/CIMAR - Interdisciplinary Centre of Marine and Environmental Research, University of Porto, Matosinhos, Portugal \\ ${ }^{4}$ Division of Zoology, Department of Biology, Faculty of Science, University of Zagreb, Zagreb, Croatia \\ ${ }^{5}$ Institut de Systématique, Évolution, Biodiversité ISYEB - Museum National d'Histoire Naturelle, CNRS, Sorbonne Université, EPHE, \\ Université des Antilles, Paris, France \\ ${ }^{6}$ CNR-IRSA Institute of Water Research, Verbania Pallanza (VB), Italy \\ ${ }^{7}$ Faculty of Biotechnology and Food, Agricultural University of Tirana, Tirana, Albania \\ ${ }^{8}$ Centro de Investigação de Montanha (CIMO), Instituto Politécnico de Bragança, Campus de Santa Apolónia, $5300-253$ Bragança, \\ Portugal \\ ${ }^{9}$ Institute of Zoology, Poznań University of Life Sciences, Poznań, Poland \\ ${ }^{10}$ CITAB-UTAD - Centre for Research and Technology of Agro-Environment and Biological Sciences, \\ University of Trás-os-Montes and Alto Douro, Forestry Department, Vila Real, Portugal \\ ${ }^{11}$ CIBIO/InBIO - Research Center in Biodiversity and Genetic Resources, University of Porto, Campus Agrário de Vairão, \\ Vairão, Portugal
}

Received: 8 November 2019 / Accepted: 13 December 2019

\begin{abstract}
We report for the first time that the freshwater mussel Microcondylaea bonellii (Férussac, 1827) functions as a suitable host for the European bitterling Rhodeus amarus (Bloch, 1782). Given the recent expansion of $R$. amarus in Europe, the possible physiological cost (e.g. competition for oxygen, reduction in water circulation, and consequent impairment of filter-feeding) of this interaction may further affect the already poor conservation status of $M$. bonellii populations.
\end{abstract}

Keywords: Conservation / ecology / freshwater mussels / non-native species / threat

Résumé - Microcondylaea bonellii, un nouvel hôte pour la bouvière Rhodeus amarus. Nous signalons pour la première fois que la moule d'eau douce Microcondylaea bonellii (Férussac, 1827) sert d'hôte à la bouvière Rhodeus amarus (Bloch, 1782). Étant donné l'expansion récente de $R$. amarus en Europe, le coût physiologique possible de cette interaction (par exemple la compétition pour l'oxygène, la réduction de la circulation de l'eau et l'altération conséquente de l'alimentation par filtration) pourrait affecter davantage le statut de conservation déjà mauvais des populations de M. bonellii.

Mots-cles : Conservation / écologie / moules d'eau douce / espèces non indigènes

\section{Introduction}

Bitterlings (Fish: Cyprinidae) and freshwater mussels (Bivalvia: Unionida) have an interesting life cycle given that

\footnotetext{
*Corresponding author: rg.eco.sousa@gmail.com
}

the embryos need a suitable host to complete their development. In bitterlings, embryos are initially brooded in a suitable freshwater mussel (for a review see Smith et al., 2004). Conversely, freshwater mussels need a suitable fish as a host to complete their life-cycle (for a review see Modesto et al., 2018). In bitterlings, females possess long ovipositors to 
A

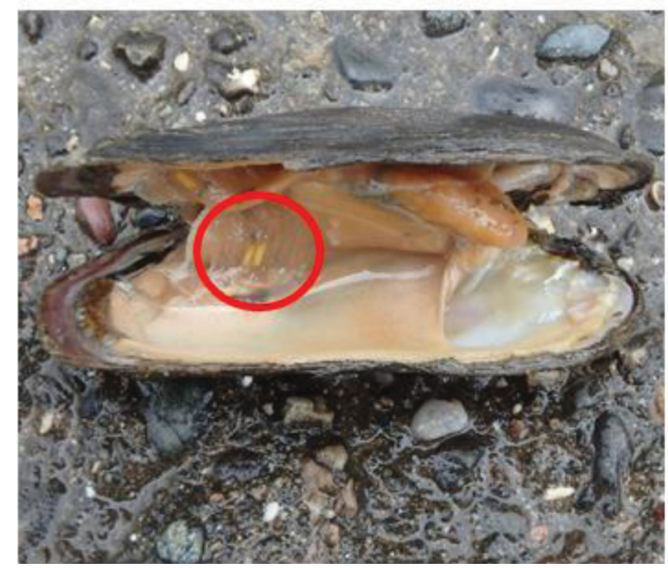

B

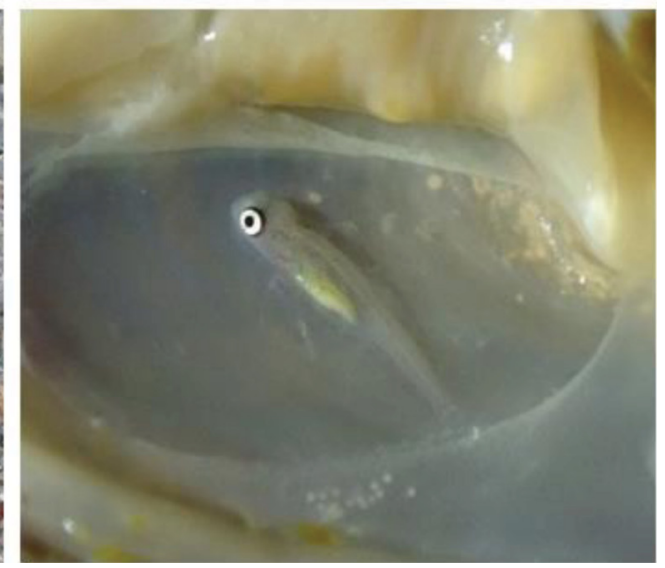

Fig. 1. A. Two embryos of European bitterling in Microcondylaea bonellii. B. An almost developed bitterling juvenile inside Microcondylaea bonellii.

deposit their eggs in the gills of freshwater mussels (via the exhalant aperture) and males fertilize these eggs releasing sperm into the mussels' inhalant aperture (Smith et al., 2004). The fertilized eggs will then develop inside the suitable freshwater mussel, leaving the host around one month later as an active juvenile (Smith et al., 2004). On the other hand, freshwater mussels have a myriad of different strategies to infest their hosts (e.g. using mantle lures, broadcasting masses of larvae, release of larvae packages in conglutinates that resemble food items, development of a lure to capture the fish host between the valves, among others) and larvae (glochidia) will then spend some time, from a few days to several months, depending on species, on the fins and/or gills of the suitable host until complete metamorphosis into juvenile mussels (Barnhart et al., 2008; Modesto et al., 2018).

Despite some controversy about the number of bitterling species colonizing Europe, Rhodeus amarus (Bloch, 1782) is considered the most widespread species on the continent (Bartáková et al., 2019). In Europe, freshwater mussel species described as possible viable hosts for bitterlings are: Anodonta anatina (Linnaeus, 1758), Anodonta cygnea (Linnaeus, 1758), Potomida littoralis (Cuvier, 1798), Pseudanodonta complanata (Rossmässler, 1835), Pseudunio auricularius (Spengler, 1793), Unio crassus Philipsson, 1788, Unio mancus Lamarck, 1819, Unio pictorum (Linnaeus, 1758) and Unio tumidus Philipsson, 1788 (revised in Soler et al., 2019). Therefore, only 7 of the 16 currently recognised European freshwater mussel species (Lopes-Lima et al., 2017) are not documented as suitable hosts for bitterlings, possibly due to the lack of overlapping distribution (Prié, 2017; Soler et al., 2019).

In this report, we describe for the first time, that the freshwater mussel Microcondylaea bonellii (Férussac, 1827) may also be considered a suitable host for R. amarus (Fig. 1A and B). During a survey in July 2019 in the Skadar Lake basin (Albania) bitterling embryos (identified visually) in different stages of development were found inside M. bonellii. In Drin River $(41.890205,19.571525)$, of a total of $7 \mathrm{M}$. bonellii analysed, 4 had bitterling embryos (57.1\%) and in Gjadër River (41.905293, 19.581752), 8 of 14 M. bonellii analysed had bitterling embryos (57.1\%). These levels of infestation are much higher than the ones described for U. crassus in Poland (4.25\%) (Tatoj et al., 2017) but lower than the $100 \%$ described for Anemina globosula (Heude, 1878) individuals infested by Rhodeus ocellatus (Kner, 1866) embryos (Reichard et al., 2007). These high levels of infestation, in comparison to other European studies, may translate in a higher energetic cost for M. bonellii (Methling et al., 2019 and see below further discussion). In addition to $M$. bonellii, A, anatina and $U$. crassus were also present in Drin and Gjadër Rivers, respectively. Anodonta anatina was also parasitized by $R$. amarus (1 of 5 individuals; $20 \%$ of infestation) but no $U$. crassus was found with bitterlings embryos in a total of 5 individuals analysed.

Rhodeus amarus is rapidly expanding its distribution and increasing their abundance in Europe mostly due to the increasing number of accidental (e.g. waterways between different systems) and/or deliberate (hobbyists and anglers) introductions by humans, and the rise in temperature in response to climate change (Van Damme et al., 2007). Albania seems to be no exception to this recent increase in spatial distribution due to human activities because recent molecular data showed that the specimens colonizing Skadar and Prespa Lakes were introduced from the Danube (Bartáková et al., 2019). In fact, a recent study reported the rapid spread and very high densities of Pseudorasbora parva and $R$. amarus in Greater Prespa Lake, mainly near the shore (Shumka and Apostolou, 2018). It is possible that $R$. amarus will further expand their spatial distribution in Albania and negatively impact freshwater mussels in this region. Microcondylaea bonellii is classified as Vulnerable by the IUCN Red List and major threats to its conservation include pollution and natural systems modifications, mainly the transformation of lotic to lentic habitats due to the presence of dams or other physical obstacles (Lopes-Lima et al., 2017). Given this threatened status the additional physiological stress caused by the infestation of bitterling embryos may be problematic. In fact, this biotic relationship between freshwater mussels and bitterlings was first classified as mutualistic, given that the bitterlings use mussel gills as spawning sites and mussels use bitterlings as hosts for glochidia (Smith et al., 2004). However, recent studies suggest that European bitterlings should be 
regarded as parasites of mussels since $R$. amarus rarely hosts glochidia of freshwater mussels (Reichard et al., 2006) and the presence of bitterling embryos in mussels has a physiological cost (e.g. competition for oxygen and reduction in water circulation and consequent impairment of filter-feeding) to the host (Smith et al., 2001; Mills et al., 2005; Prié, 2017; Methling et al., 2019). These negative effects may reduce growth and affect fecundity of freshwater mussels (Reichard et al., 2006). In addition, freshwater mussels parasitized with multiple clutches of bitterling eggs experienced high mortality in mesocosms; although almost no data exist for wild populations (Smith et al., 2000; Reichard et al., 2010).

The recent expansion of $R$. amarus into new regions and countries, including Albania, has led to an increasing contact with a larger number of freshwater mussel species, including $M$. bonellii. Our results confirm for the first time that $R$. amarus may parasitize $M$. bonellii and this situation appears to confirm the recent hypothesis raised by Soler et al. (2019) that this fish species is able to spawn in any European unionid mussel. In addition, freshwater mussels are actively developing antibitterling adaptations (e.g. decreasing the success of oviposition and expelling bitterling eggs and embryos; Smith et al., 2000; Reichard et al., 2010). From this point of view, in European areas historically without any bitterling species, these adaptations are possibly missing and $R$. amarus may benefit from exploiting novel hosts, which may not possess appropriate adaptive responses to parasitism (Rouchet et al., 2017). This situation should be further investigated given the high imperilment faced by several European freshwater mussels, including M. bonellii.

Acknowledgments. We acknowledge the two anonymous referees for the helpful suggestions that improve the clarity of our manuscript. This research was funded by FCT under project ConBiomics N ${ }^{\circ}$ NORTE-01-0145-FEDER-030286, cofinanced by COMPETE 2020, Portugal 2020 and the European Union through the ERDF.

\section{References}

Barnhart MC, Haag WR, Roston WN. 2008. Adaptations to host infection and larval parasitism in Unionoida. J N Am Benthol Soc 27: 370-394.

Bartáková V, Bryja J, Šanda R, et al. 2019. High cryptic diversity of bitterling fish in the southern West Palearctic. Mol Phylogenet Evol 133: 1-11.

Lopes-Lima M, Sousa R, Geist J, et al. 2017. Conservation status of freshwater mussels in Europe: state of the art and future challenges. Biol Rev 92: 572-607.
Methling C, Douda K, Reichard M. 2019. Intensity-dependent energetic costs in a reciprocal parasitic relationship. Oecologia 191: 285-294.

Mills SC, Taylor MI, Reynolds JD. 2005. Benefits and costs to mussels from ejecting bitterling embryos: a test of the evolutionary equilibrium hypothesis. Anim Behav 70: 31-37.

Modesto V, Ilarri M, Souza AT, et al. 2018. Fish and mussels: Importance of fish for freshwater mussel conservation. Fish Fish 19: 244-259.

Prié V. 2017. Newly overlapping ranges: First records of Potomida littoralis (Cuvier, 1798) infestation by the European Bitterling Rhodeus amarus (Bloch, 1782). J. Conchol 42: 381-382.

Reichard M, Liu H, Smith C. 2007. The co-evolutionary relationship between bitterling fishes and freshwater mussels: insights from interspecific comparisons. Evol Ecol Res 9: 1-21.

Reichard M, Ondrackova M, Przybylski M, Liu H, Smith C. 2006. The costs and benefits in an unusual symbiosis: experimental evidence that bitterling fish (Rhodeus sericeus) are parasites of unionid mussels in Europe. J Evolution Biol 19: 788-796.

Reichard M, Polačik M, Tarkan AS, et al. 2010. The bitterling-mussel coevolutionary relationship in areas of recent and ancient sympatry. Evolution 64: 3047-3056.

Rouchet R, Smith C, Liu H, et al. 2017. Avoidance of host resistance in the oviposition-site preferences of rose bitterling. Evol Ecol 31: 769-783.

Shumka S, Apostolou A. 2018. Current Knowledge on the Status of the Most Common Non-Indigenous Fish Species in the Transboundary Greater Prespa Lake (Albanian Side). Acta Zool Bulgar 70: 203-209.

Smith C, Reichard M, Jurajda P, Przybylski M. 2004. The reproductive ecology of the European bitterling (Rhodeus sericeus). J Zool 262: 107-124.

Smith C, Reynolds JD, Sutherland WJ, Jurajda P. 2000. Adaptive host choice and avoidance of superparasitism in the spawning decisions of bitterling (Rhodeus sericeus). Behav Ecol Sociobiol 48: 29-35.

Smith C, Rippon K, Douglas A, Jurajda P. 2001. A proximate cue for oviposition site choice in the bitterling (Rhodeus sericeus). Freshwater Biol 46: 903-911.

Soler J, Wantzen KM, Araujo R. 2019. Rhodeus amarus (Bloch, 1782): a new potential threat for Margaritifera auricularia (Spengler, 1793) (Unionoida, Margaritiferidae). Freshw Sci 38: 406-411.

Tatoj K, Ćmiel AM, Kwaśna D, Lipińska AM, Zając K, Zając T. 2017. The endangered thick-shelled river mussel (Unio crassus): a new host species for the European bitterling (Rhodeus amarus). Biodivers Conserv 26: 1217-1224.

Van Damme D, Bogutskaya N, Hoffmann RC, Smith C. 2007. The introduction of the European bitterling Rhodeus amarus to west and central Europe. Fish Fish 8: 79-106.

Cite this article as: Sousa R, Bogan AE, Gonçalves DV, Lajtner J, Prié V, Riccardi N, Shumka S, Teixeira A, Urbańska M, Varandas S, Lopes-Lima M. 2020. Microcondylaea bonellii as a new host for the European bitterling Rhodeus amarus. Knowl. Manag. Aquat. Ecosyst., $421,4$. 